\title{
Sizing of the Sustainable Irrigation System by Using of the Critical Period Method: Case Study of the Football Club 'Obreš', Sveti Ilija, Croatia
}

\author{
Bojan Đurin \\ Faculty of Geotechnical Engineering \\ University of Zagreb \\ Croatia
}

\begin{abstract}
System approach and sustainable use of water and energy in all kinds of human activities is not required for financial reasons only. It is also a legal and community obligation. The paper deals with the application of Critical Period Method for irrigation system design on case study of the local football club "Obreš", on location of Sveti Ilija, Croatia. Two variants of the irrigation system are considering, Variant I and Variant II. Both of the variants of the irrigation system includes a solar photovoltaic $(P V)$ generator and inverter, a pump station, a water reservoir and pipelines. Variant I is based on the water tower reservoir, while Variant II is based on the solar batteries. PV energy is used as energy source for the pump station. Groundwater in combination with rainwater is used for irrigation water demands. Proposed solution is in accordance with the world and European legislation, directives and strategies related to the negative impacts of climate changes and greenhouse gas emissions.
\end{abstract}

\section{Introduction}

Water supply is of great importance for the sustainability of both urban and rural areas throughout the world. Given the negative climate changes, increasing and more frequent pollution of groundwater and surface water, and reducing volumes of available sources of fossil fuels, which today is used extensively as a source of energy, sustainable use of water and energy by itself becomes imperative.

Legal provisions contained in a number of guidelines and accompanying regulations also contribute to such reasoning. An important segment of sustainable urban and rural areas is the use of water and energy for irrigation of green areas, grass sports fields, gardens, orchards, nursery-gardens, etc.

The primary task of a water supply system is to ensure adequate quality and quantity of water for the needs of both population and industry. However, other segments of water uses including irrigation should not be ignored.

In comparison to all other renewable energy sources (RES), solar photovoltaic (PV) energy is the most suitable form for various uses in water supply ([1-8] and many others). The irrigation system analyzed includes a solar photovoltaic (PV) generator and inverter, a pump station, a water reservoir and pipelines. PV energy is used as energy source for the pump station to supply the reservoir with water. The water from the reservoir is dispatched to a grass lawn via the pipelines.

Regardless of the existing technology and methodology of using PV system in the water supply system, the viability of such systems ([1-8] and many others) has been studied recently. The elaborated sizing procedure using the Method of Worst Month, [5], has been improved in [2] and [8], using the original and innovative designed Critical Period Method, which was used for the sizing of the water supply system of the settlement. In doing so, each part of the water supply system is separately sized with respect to its corresponding critical day/period of the year. The Critical Period Method will be modified for application in irrigation for it involves certain specific characteristics which affect the relationships of all parts of the system. This will be described in the case of pitch irrigation of a local football club "Obreš" on location of Sveti Ilija, near Varaždin in Croatia. For irrigation water demands, groundwater is used in combination with rainwater.

\section{Concept and description of the observed irrigation system}

This paper analyses two variants of an autonomous water supply system using PV energy to drive the pump station which pumps the water into the water reservoir; Variant I and Variant II, (Figure 1.), which uses solar batteries. 


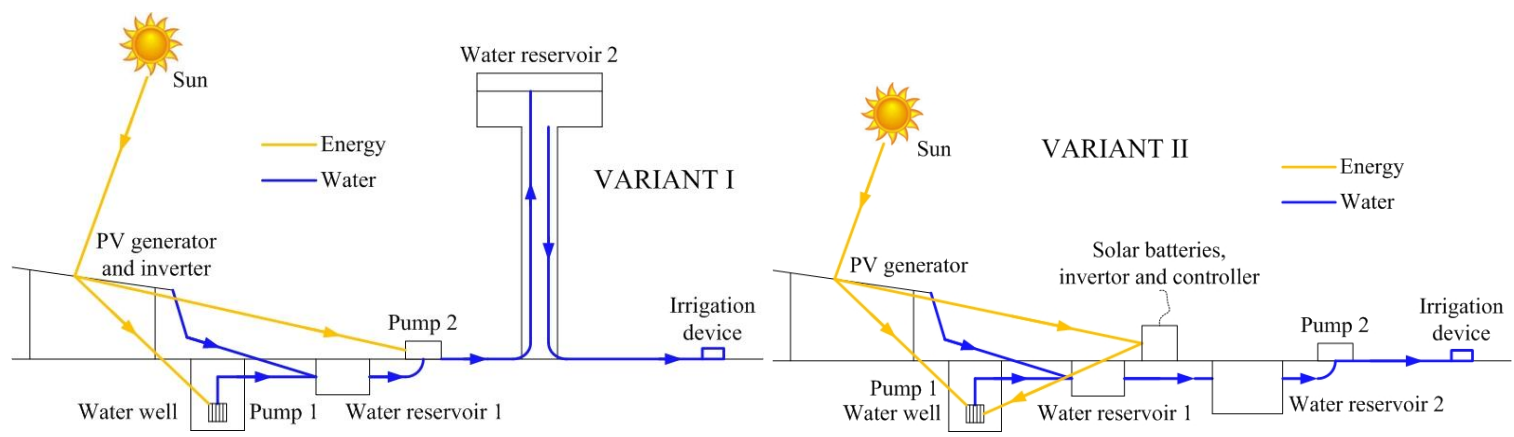

Figure 1. Schematic representation of the observed irrigation system variants (Variants I and II)

In Variant I, PV cells, which form the PV generator, are used for the conversion of solar radiation into direct current power, which is converted by inverters into alternating current necessary for pump drive. In case the pump station is powered by direct current pumps, the inverter is not required. Available insolation $E_{s}$, i.e., electric energy $P_{e l, P V}$ determines the period of the pump station operation Ts with uniform rate during daily work period. Variant II has the same working principle; the difference is that water is stored in the surface water reservoir and pumped over to the irrigation device using electrical energy stored in solar batteries.

In both variants it is necessary to set up minimum two pumps. First pump (pump 1 in a well) is used to pump water from a well and deliver it to the water reservoir 1. Rainwater (precipitation water) is collected in this water reservoir. Rainwater is collected from the existing roofs and PV cells via grooves for water discharge into the water reservoir 1. If the roof or the solar cells are at a sufficient height, the rainwater is drained by gravity (free fall). In case such gravitational flow is not possible, it is necessary to install a "booster" pump for pumping over. It should be noted that this water reservoir does not function as a pumping tank or conventional water reservoirs for flow and consumption equalization, since both pumps operate when the intensity of solar radiation is at its optimal operating level. This implies that the hourly, as well as daily input is the same as hourly/daily output from this water reservoir, so there is no need to provide for the volume equalization. In Variant I, water is drawn by surface pump 2 from the water reservoir 1 into the water reservoir 2 where water is collected and distributed to the areas being irrigated. Variant II has the same working principle; the only difference is that the water from water reservoir 1 is coming into surface water reservoir 2 in most of the cases by gravity or by ' 'booster' " pump, if it is not possible to provide flow by gravity. These types of irrigation can be also used for enclosed areas (greenhouses). Typically, water is pumped over into a water reservoir during the day while the irrigation takes place at night, which is more suitable for the vegetation, with the reduced evapotranspiration as well. The distribution of water from water reservoir to the crops is mainly gravitational in Variant I, since the water reservoir is situated at a certain height above the ground surface thus achieving the required water pressure. In Variant II water is distributed by pump 2.

In any case, it is necessary to provide the required volume of the water reservoir 2, namely the water required to meet the irrigation needs. Primarily this need will be provided by pumping groundwater, with a certain amount obtained from rainwater. However, an additional volume of rainwater will not be foreseen for the water reservoir 2, since it is assumed that this quantity of water will be considerably lower than the planned amount of water drawn from the well. Rainwater has an additional purpose of mixing with underground water, which makes it more suitable for the irrigated vegetation. In addition, this amount of water to some extent also relieves the underground aquifer layer.

The last part of the observed system includes the output pipelines from the water reservoir. In this case one can predict the irrigation of an area based on the installed connected pipelines or irrigation devices.

\section{Methodology for sizing a sustainable irrigation system}

\subsection{Sizing of all parts of the observed system}

Power of a subsystem PV, $P_{e l, P V}$ (W) which generates electrical energy for pumping the water to water reservoir at a certain period of time $i$, representing days of the year, $i=1,2, \ldots 365$ days, is equal to [2], [8]:

$$
P_{e l, P V(i)}=\frac{2.72 H_{P S(i)}}{\left[1-\alpha_{c}\left(T_{\text {cell }(i)}-T_{0}\right)\right] \eta_{P S I} E_{s(i)}} V_{P S(i)}
$$

where $H_{P S(i)}(\mathrm{m})$ is manometer height, $V_{P S(i)}$ $\left(\mathrm{m}^{3} /\right.$ day) is daily amount of water pumped into the water reservoir at a certain time period (day) $i, \alpha_{c}$ is solar cell temperature coefficient $\left({ }^{\circ} \mathrm{C}\right), T_{\text {cell }}$ is solar cell mean daily temperature $\left({ }^{\circ} \mathrm{C}\right), T_{0}$ is solar cell 
mean daily temperature in standard test conditions, which is $25^{\circ} \mathrm{C}, \eta_{P S I}$ is pump station and inverter mean efficiency $(\%), E_{s(i)}\left(\mathrm{kWh} / \mathrm{m}^{2}\right)$ is available mean daily average intensity of solar radiation for the time interval $i$.

Electricity produced, $E_{e l, P V(i)}(\mathrm{Wh})$, in period $T_{i}$ is expressed by [2], [8]:

$$
E_{e l, P V(i)}=P_{e l, P V(i)} \times T_{i}
$$

Mean daily temperature of a solar cell, $T_{\text {cell( }(i)}$, is obtained using [2], [8]:

$$
T_{\text {cell( }(i)}=2.7 \times E_{s(i)}+T_{a(i)}
$$

where $T_{a(i)}$ is a mean daily air temperature $\left({ }^{\circ} \mathrm{C}\right)$.

Mean efficiency of the pump station and inverter $\eta_{P S I}$ is obtained as [2], [8]:

$$
H_{P S I}=\eta_{P S} \times \eta_{I}
$$

where $\eta_{P S}$ is pump station efficiency, while $\eta_{I}$ is inverter efficiency.

For a given power of a subsystem PV, $P_{e l, P V(i)}$, the possible amount of water $V_{P S(i)}\left(\mathrm{m}^{3}\right)$, pumped into the water reservoir during the time interval $i$ is equal to:

$$
V_{P S(i)}=\frac{\left\lfloor 1-\alpha_{c}\left(T_{\text {cell }(i)}-T_{0}\right)\right\rfloor \eta_{P S I} E_{s(i)}}{2.72 H_{P S(i)}} P_{e l, P V(i)}
$$

The required area of a $\mathrm{PV}$ generator $A_{P V}\left(\mathrm{~m}^{2}\right)$ is obtained from [2], [8]:

$$
A_{P V}=\frac{P_{e l, P V}}{1000 \eta_{P V}}
$$
PV.

where $\eta_{P V}$ is a mean efficiency of a subsystem

In case all the available daily solar energy $E_{s}$, or electricity produced, will be used for pumping $V_{P S(i)}$ into the water reservoir, the average necessary capacity of the pump station $Q_{P S \text {,available(i) }}$ will then be equal to [2], [8]:

$$
\begin{aligned}
& Q_{P S, \text { available } i)}=\frac{V_{P S(i)}}{T_{s(i)}}= \\
& =\frac{P_{e l, P V}}{T_{s(i)}} \frac{\left[1-\alpha_{c}\left(T_{c e l l}-T_{0}\right)\right] \eta_{P S I} E_{s(i)}}{2.72 H_{P S(i)}}
\end{aligned}
$$

namely:

$$
Q_{P S} \geq \max Q_{P S, \text { availablei) }}
$$

$T_{S}$ is the daily number of peak sun hours or usable duration of insolation, which is obtained by the [5]:

$$
T_{s}=\frac{E_{s}}{1000}
$$

The number of peak sun hours is merely an estimation of the amount of time per day that the irradiance is equal to a peak Sun, and because PV models are rated for their output under peak sun conditions, the number of daily peak sun hours indicates how many hours of each day the PV array will operate at its full power output.

However, if all water quantity $V_{P S(i)}$ does not necessarily need to be pumped over, namely if the water quantity $V_{P S(i)}$ is greater than the required amount of water for the population needs $V_{\text {daily }(i)}$, then minimal average required pump capacity $Q_{C S \text {,needed(i) }}$ is equal to:

$$
Q_{P S, \text { needed }(i)}=\frac{V_{\text {daily }(i)}}{T_{s(i)}}
$$

Since the purpose of the pump is pumping (lifting) water into the water reservoir, the required capacity $Q_{P S}^{*}$ is:

$$
Q_{P S}^{*}=\max \left(Q_{P S, \text { needed }(i)}\right)
$$

Average power of the pump station $P_{P S}^{*}$ is then:

$$
P_{P S}^{*}=\frac{\rho g Q_{P S}^{*} H_{P S}}{\eta_{P S}}
$$

where $\eta_{P S}$ is average efficiency of the pump station.

Water reservoirs are typically sized for one-day water equalization of supply and consumption for a day with maximum consumption, but equalization can also be done for more days, up to seven. Operating volume of the water reservoir $V_{o p(i)}$ is defined for each day in a year by method of integral curve, i.e. Ripley method [2], [8]:

$$
V_{o p(i)}=\max \left[\sum_{t=1}^{24}\left(Q_{P S(t)}-Q_{\text {hour }(t)}\right)\right]
$$

where $t=1,2, \ldots, 24 \mathrm{~h}$.

Equation (13) applies if within a period of $t=1$ hour up to 24 hours (one day) the water inflow of the water reservoir is the same as water outfall from the water reservoir. It is a simple methodology based on the fact that within the period of exchange, which can be the period of one up to seven days, all the water inflow is the same as the outfall from the reservoir.

Size, or the capacity of the solar battery $C_{B}$ (Ah) is obtained using the formula, taken and adapted from [5]:

$$
C_{B}=\frac{E_{e l, P V}}{D O D \times V_{s y s} \times \eta_{B}} \times t_{b}
$$

whereby the depth of the discharge $D O D$ of the solar battery $(\%), V_{\text {sys }}$ is the system voltage $(\mathrm{V}), \eta_{B}$ is the solar battery efficiency and $t_{b}$ is the balancing period (days).

\subsection{Critical Period Method}

In this paper we used the approach based on critical design period, whereby the Critical Period Method was devised [2], [8]. This approach includes design elements of the solution: PV system, pump station and water reservoir based on the critical period of operation of each one. It is also a conservative approach, meaning that the elements of the solution are potentially overdesigned. However, such an approach provides a reliable solution and a required level of reliability, necessary for the functioning of water supply systems. The reliability of the bulk water supply system can be defined in 
terms of reliability of its storage reservoir/tank, as consumers will only notice a service interruption if the storage tank has failed (i.e., run dry).

The balancing period of water pumping and water reservoir water balance is usually at least one day and may be several days, usually no more than five, $\left(t_{b}=1\right.$ till 5 days $)$. A longer balance period reduces the uncertainty of solar irradiation and increases the reliability of the solution. With a longer balancing period, the system is more cost-effective from the perspective of solar energy harvesting, because the sum of overall available solar radiation is greater when the balancing period is longer. This means that the required water volume can be pumped with lower installed PV system power $P_{e l, P V}$. Normally, with a longer balancing period, the storage capacity of the reservoir $V_{o p}$ will be higher.

At the beginning of the analysis it is necessary to define the daily quantity of water for irrigation purpose $V_{\text {daily }}\left(\mathrm{m}^{3} /\right.$ day), according to the vegetation characteristics and water consumption regime throughout the analyzed months of the planning period. After this, the daily water usage pattern $V_{\text {daily,t }}$ $\left(\mathrm{m}^{3} / \mathrm{h}\right)$ in the period of $t=1,2, \ldots, 24$ hours is determined (diurnal pattern). It is assumed that the same pattern is used for each day and throughout the analyzed months.

Based on the obtained values, the minimum required size of the PV system is determined, which provides the necessary inflow of water in the critical period. Based on the selected/calculated initial values, $P_{e l, P V}$ and $V_{P S}$, which satisfy water demand $V_{\text {daily }}$ in the planning period, the minimum required $P_{e l, P V}$ is determined from established differences $\Delta V_{t b, i}$ :

$$
\Delta V_{t b, i}=V_{P S, t b, i}-V_{d a i l y, t b, i}
$$

The critical day/period for PV generator design is determined by the minimum daily difference using statistical minimization:

$$
\min \Delta V_{t b, i} \Rightarrow t_{P e l, P V, t b, i}^{*}
$$

where $\Delta V_{t b, i}$ is an acceptable difference in practice application which is typically equal to 0 .

The required operation volume of water reservoir 2, $V_{o p}$, is obtained using the (13). Time step for calculation is one hour, $t=1,2 \ldots, 24$ hours. In general, the critical day/period for the design of volume reservoir $t_{V, t b, i}^{*}$ is the day with maximum water demand and the shortest duration of solar radiation suitable for pump station operation, providing that on the available day insolation $E_{s(i)}$ is sufficiently high. A critical day/period for the pump station $t_{P S, t b, i}^{*}$ also coincides with this critical day. It should be noted that the fire volume is not taken into account for this case, because in this case there are water needs only for irrigation. Also, it is not foreseen to provide additional volume of water reservoirs for emergency situations since it is meant irrigation. Based on the above mentioned, the required volume for each alternative tb is obtained using statistical maximization, with the associated critical day:

$$
V_{o p}^{*} \geq \max V_{o p, i}=>t_{V, t b, i}^{*}
$$

As a rule, the critical day $t_{V, t, i}^{*}$ refers to the day in which the daily duration of solar radiation $T_{s}$, which is suitable for pumping, is shortest during the analyzed year.

The same situation applies to the capacity of pump stations:

$$
Q_{P S}^{*} \geq \max Q_{P S}=>t_{P S, t b, i}^{*}
$$

Daily quantity of water for irrigation purpose $V_{\text {daily }}\left(\mathrm{m}^{3} /\right.$ day $)$ is obtained to the most part by pumping groundwater and to a lesser extent from rainwater. Due to stochastic nature of the rain, the safest option is providing backup volume of water reservoir 1 of a same volume as the quantity of collected rainwater. At the same time this size represents the additional quantity of water for emergency situations.

\section{Case study and input data}

\subsection{Location}

The described methodology of sizing the irrigation system will be illustrated on the example of pitch irrigation for the local football club 'Obreš', located near Varaždin, Croatia, on the territory of Sveti Ilija municipality (Figure 2.), [9], [10]. The football pitch covers the area of $105 \times 70$ $\mathrm{m}$. The altitude of the location is $173 \mathrm{~m}$ asl. Figure 3., [9], shows the position of all elements of the analyzed system for variants I and II. According to the recommendations from bibliography [6] and the position of the available area, the azimuth (angle spread) of the PV generator is in the south direction, while the angle of inclination is equal to $15^{\circ}$. 




Figure 2. Location of the municipality Sveti Ilija, Croatia
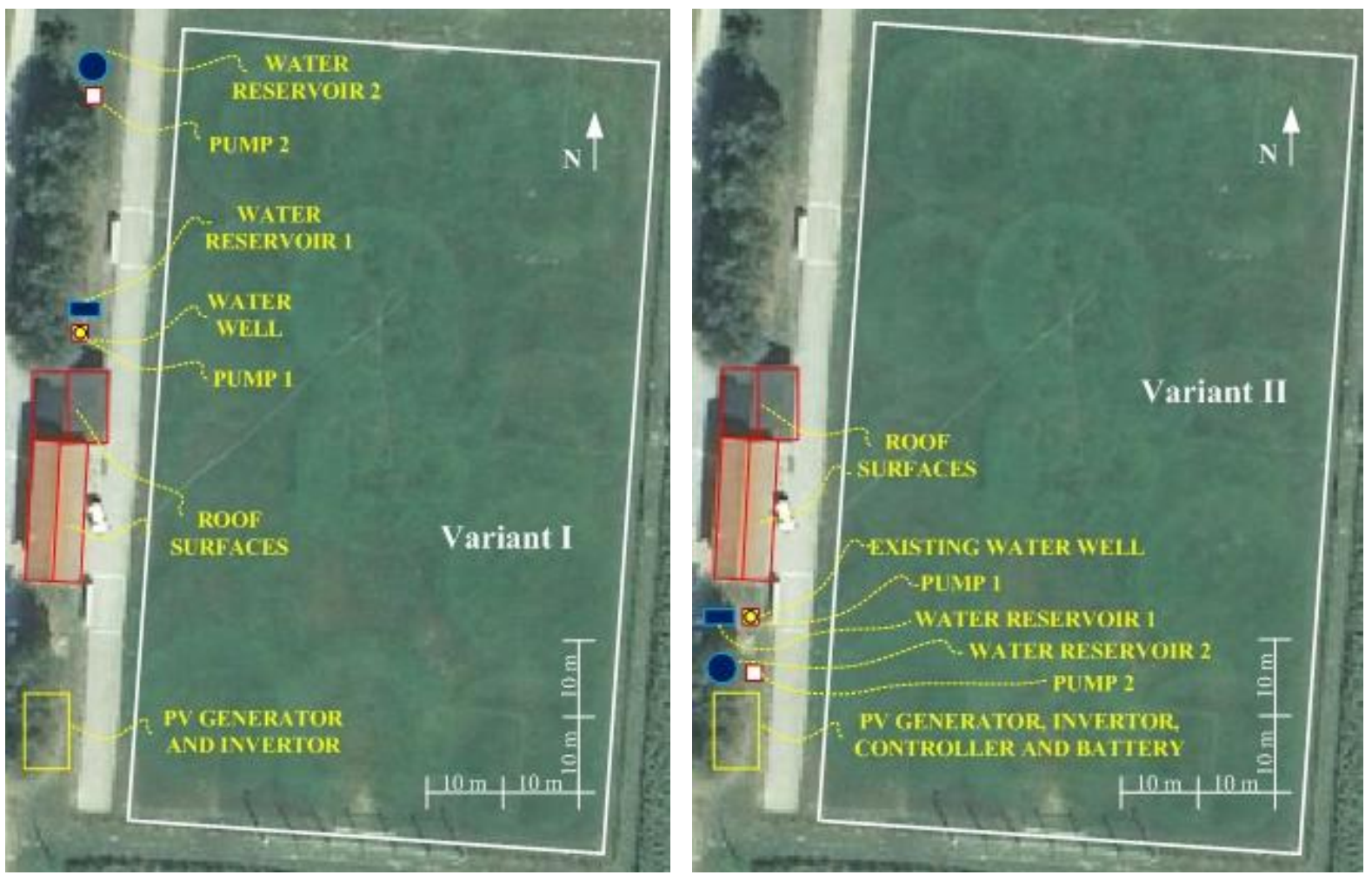

Figure 3. Overview of the football pitch of Football Club Obreš with elements of Variants I and II

Groundwater, which is situated in shallow layers at a depth of $5 \mathrm{~m}$, is used for irrigation, and the usage of the existing well showed that its capacity is sufficient. Another favorable fact is that the location is situated in the area of rich Varaždin aquifer [11]. Since the biggest problems include the impracticality of the existing irrigation system with rubber hoses, unsustainable water and energy consumption, as well as insufficient capacity of the existing lifting pump in the well, there is a plan to build a new, more modern and sustainable irrigation system. 


\subsection{Input data}

According to the recommendations from the bibliography [12] and the actual needs, the adopted daily constant water need (consumption) $V_{\text {daily }}$ from
May to August, and within these 4 months amounts to $30 \mathrm{~m}^{3}$. The football pitch is not irrigated during other periods of the year. There are two daily regimes of water consumption, i.e. water inflow and outfall (input/output) of water reservoir (Figure 4.).

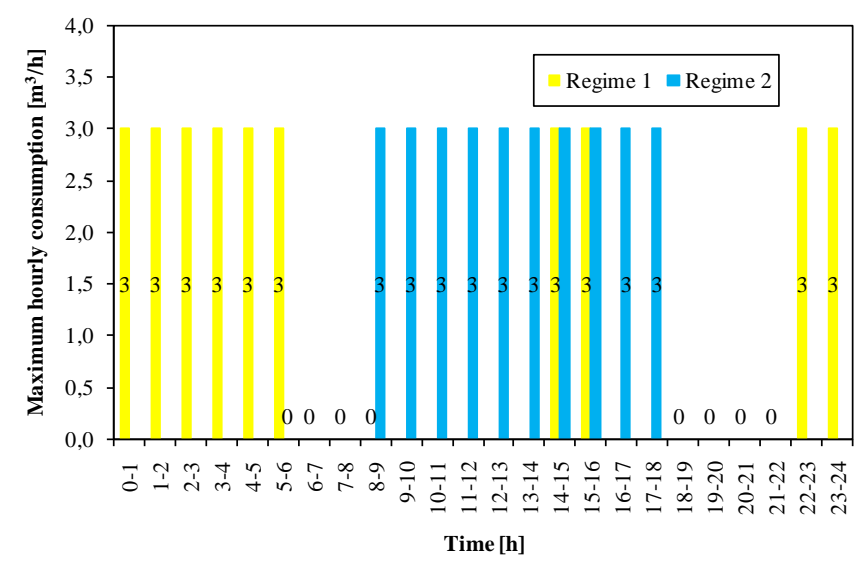

Figure 4. Daily regimes of football pitch irrigation

Regime 1 is more favorable if the pitch is busy during the day, and also it is more suitable for the grass if irrigation takes place during the night. Regime 2 is more practical considering the possibility of theft of the irrigation equipment, as well as the need to impose security measures for its prevention (alarms, physical protection).

Figure 5. shows average daily insolation intensity [13], peak hours period (9), average daily air [14]
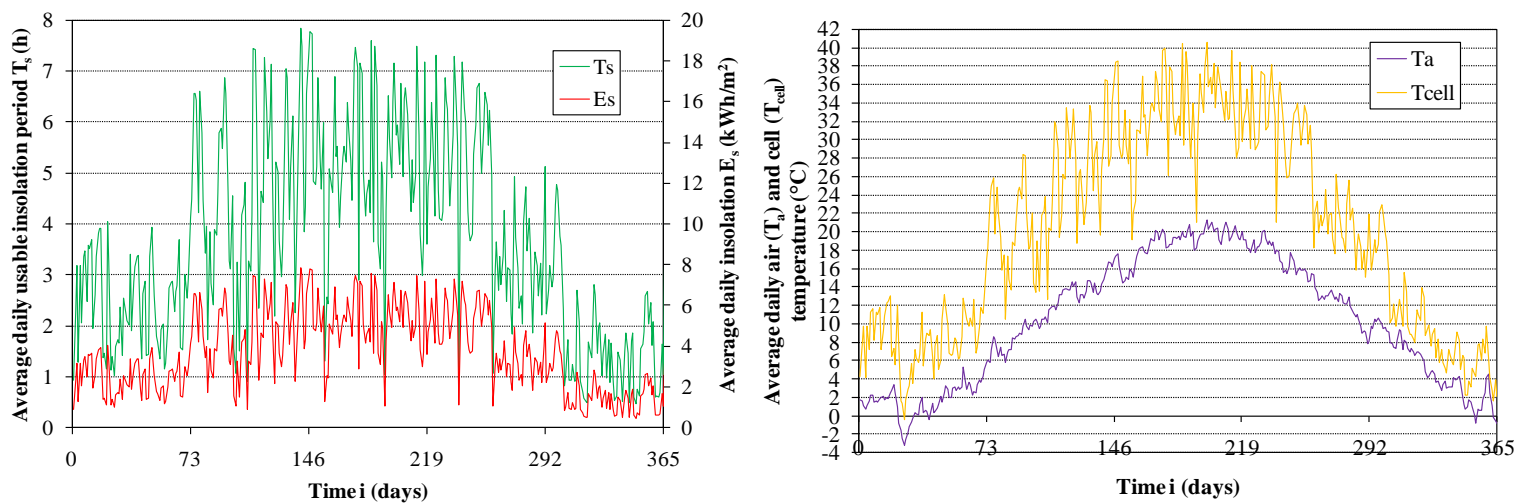

Figure 5. Average daily usable insolation period, insolation intensity, average daily air and solar cell temperature 


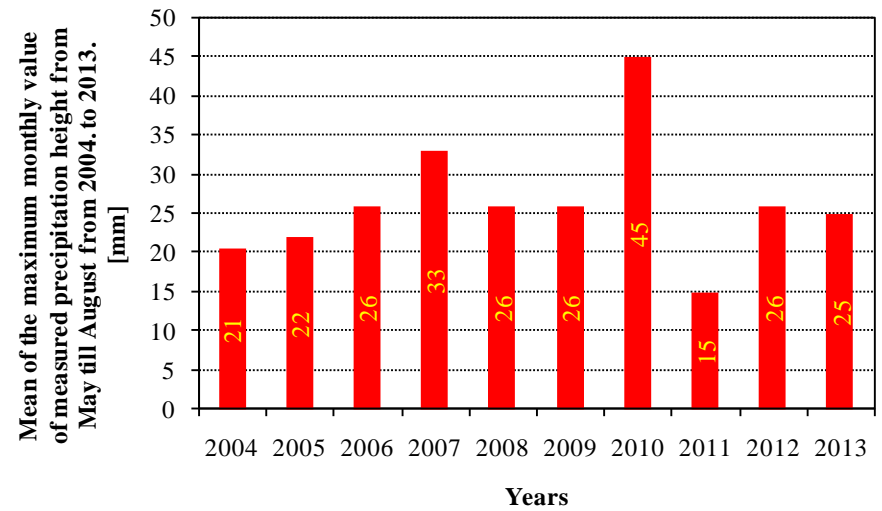

Figure 6. Mean of the maximum monthly value of measured precipitation height from May till August from 2004. to 2013.

\section{Obtained results and discussion}

For the purposes and within the scope of this scientific work, the sizing procedure will be carried out for the period of balancing one day only $\left(t_{b}=1\right.$ day). Critical days for sizing of all parts of the subsystem are, according to the (16-18) and starting with first day of the year, for the subsystem PV: $t_{P e l, P V, t b, i}^{*}=239^{\text {th }}$ day, for the subsystem V: $t_{V, t b, i}^{*}=$ $239^{\text {th }}$ day and for the subsystem CS: $t_{P S, t b, i}^{*}=239^{\text {th }}$ day. Typically, critical days differ, [2], but if the water consumption regime is constant, they overlap, as shown in this example.

Taking into account the estimated total pressure losses in all the pipelines, secured height to prevent cavitation, as well as the required pressure of $3.5 \mathrm{bar}$ for operation of the irrigation device [12], the adopted height of the water reservoir is $50 \mathrm{~m}$, with the adopted pipeline diameter of $5 \mathrm{~cm}$ (as well as all pipelines) to the water reservoir. Pipe material is cast iron with bitumen, roughness coefficient is $0.1 \mathrm{~mm}$, while the operating roughness coefficient is $0.11 \mathrm{~mm}$ (with the increase of $10 \%$ to compensate local losses). The total calculated manometer height of a submersible well pump (with total pressure losses included, as well as secured height to prevent cavitation) is $10 \mathrm{~m}$.

Water is delivered from water reservoir 1 to water reservoir 2 by surface pump 2. The minimum or maximum speed range for water flow in inlet pipelines in both water reservoirs ranges from 0.5 $\mathrm{m} / \mathrm{s}$ up to $2 \mathrm{~m} / \mathrm{s}$ with respect to minimum $\left(3.75 \mathrm{~m}^{3} / \mathrm{h}\right)$ and maximum $\left(15 \mathrm{~m}^{3} / \mathrm{h}\right)$ hourly input water flow values to reservoirs 1 and 2 . This means that the adopted capacity for both pumps is $15 \mathrm{~m}^{3} / \mathrm{h}$.

The necessary power of subsystem PV (PV generator and invertor) i.e. required power for pump operation is obtained using $(1,3,4,15,16)$ and adopted required input values. For the well pump 1, the required power is $6500 \mathrm{~W}$, and for the surface pump 2 the required power is $1300 \mathrm{~W}$, therefore totaling $7800 \mathrm{~W}$. The required area of PV generator amounts to $43 \mathrm{~m}^{2}$ for pump 1 and $9 \mathrm{~m}^{2}$ for pump 2, or total $52 \mathrm{~m}^{2}(6)$.

The required volume of the water reservoir 2 is 24 $\mathrm{m}^{3}$, based on $(9,11,13,17)$ and with regard to water needs, as well as both water consumption regimes (Regime 1 and 2). It should be noted that water reservoir 1 capacity is adopted based on the mean of the maximum monthly value of measured precipitation height for May till August month within the observed period of 10 years (from 2004. to 2013.), which is $26.4 \mathrm{~mm}$, Figure 6. [14].

As a rule, the amount of storm water is calculated using statistical methods, taking into account certain probabilities of occurrence and return periods, but this was not done due to the limited scope of this work as well as relatively small areas for rainwater collection. Since the water is collected from available roof areas $\left(350 \mathrm{~m}^{2}\right)$, as well as from area of PV generator $\left(52 \mathrm{~m}^{2}\right)$, the estimated quantity of storm water that may occur is $11 \mathrm{~m}^{3}$. Because of this, it is necessary to ensure a certain capacity of the reservoir 1 which is equal to this extreme amount of water, rather than equalization of water inflow from the well and flow that goes from reservoir 1 to reservoir 2.

Pump 2 power is $3406 \mathrm{~W}$ (3500 W approved), while pump 1 power is $681 \mathrm{~W}$ (700 W approved), $(10-12,18)$. Outlet pipes from water reservoirs are rubber/flexible hoses and they come with irrigation device. The required capacity of solar battery is obtained based on (14), which is $C_{B}=3250 \mathrm{Ah}$.

Considering the mean values, unit prices as well as total prices of all irrigation system elements (VAT included), and based on the available references, [2, 15 - 18], it was possible to determine the capital costs of the system for both variants, as shown in Table 1. A more detailed economic analysis was not conducted due to the purpose and scope of this paper. 
Table 1. Capital costs of individual irrigation system parts for Variants I and II

\begin{tabular}{|l|l|l|l|}
\hline Subsystem & Unit price & Size & Price (€) \\
\hline PV generator (I, II) & $1.5 € / \mathrm{W}$ & 7800 & 11700 \\
\hline PV invertor (I, II) & $0.5 € / \mathrm{W}$ & 7800 & 3900 \\
\hline Pump station 1 (I, II) & $1 € / \mathrm{W}$ & 700 & 700 \\
\hline Pump station 2 (I, II) & $1 € / \mathrm{W}$ & 3500 & 3500 \\
\hline Water reservoir 1 (I, II) & - & 11 & 1000 \\
\hline Water reservoir 2 (I, II) & - & 24 & 2700 \\
\hline Water reservoir tower (I) & - & - & 53500 \\
\hline Well (I) & - & - & 2000 \\
\hline Solar batteries (II) & $2 € / \mathrm{Ah}$ & 3250 & 6500 \\
\hline Controller (II) & - & - & 1320 \\
\hline Irrigation device with pipes (I, II) & - & - & 2000 \\
\hline Pipes (I, II) & $2 € / \mathrm{m}^{\prime}$ & $100(\mathrm{I}) ; 10$ (II) & $200 ; 20$ \\
\hline
\end{tabular}

The total capital costs for Variant I amount to $81200 €$ and for Variant II $33340 €$. Therefore, the variant with water reservoir is approximately 2.5 times more expensive than the variant with solar batteries. It is evident from Table 1 that the tower price in dominant in Variant $\mathrm{I}$.

For the presented case of rural area irrigation, the use of solar batteries is definitely more convenient than using the reservoir. However, if the variant with water reservoir (Variant I) is applied in urban area, there would be no need for suspension tower construction, since some other existing elevated structure could be used for this purpose, skyscraper for example, or the existing spotlight pillars on football stadiums etc. Also, placing a water reservoir on a hill or some other natural high ground, regardless of urban or rural area, would eliminate the need for reservoir tower installation.

Also, it should be taken into account that during the system operation over a period of 4 to 8 months, there will be an electric power surplus, which can be sold within the power distribution system, or used for other purposes. This energy is equal to $4214 \mathrm{kWh}$ on annual level. It is also necessary to consider the fact that during the period when the system is not operating (from September to April the next year), the subsystem PV generates electrical energy which can also be used as aforesaid (4550 kWh a year). Thus, the total annual surplus of generated electrical energy is equal to $8764 \mathrm{kWh}$. Annual sale price of this energy is $613 €$ (excluding VAT), [2]. If the excess generated electrical power was used for pumping water for other purposes (irrigation of other areas, orchards, glasshouses etc.), then on the annual basis $34928 \mathrm{~m}^{3}$ of water would be pumped over, which means 16142 during the irrigation period (May to August) and $18786 \mathrm{~m}^{3}$ for the remainder of the year.

\section{Conclusions and guidelines for further research}

This analysis, although simplified due to the scope and the purpose of this work, gives a realistic insight into the possibility of systemic utilization of water and energy in a rural area. The displayed conceptual solution for playground irrigation of a local football club can be applied for urban areas as well, on a local as well as regional scale. The resulting solution is conservatively selected/sized enabling high reliability of irrigation system. It also allows the use of surplus generated electricity for other purposes (lighting, operation of various electrical devices) or for sale within the electricity network. The application of the methodology described above is resulting in more rational sizing of the entire irrigation system i.e. in achieving the sustainability of systematic use of water and energy. The above statement can be read in terms of the selection of water consumption parameters/quantities and energy production, which are given as mean values in a small scale (daily, instead of monthly, as it is usually done). An important fact is that cloudy sky or precipitations do not present a big problem since irrigation is not needed in those cases. Due to small quantities of collected rainwater, in this analysis it does not replace the affected groundwater, but still ensures a certain backup volume of water. Storm water improves the quality of water used for irrigation. It is also shown that water reservoirs, apart from irrigation purposes and hydraulic function of water storage, function as energy storage as well.

This concept can also be used for irrigation of green areas for various purposes, such as orchards, gardens, farms, greenhouses and the like. If water quality is satisfactory in terms of industry or livestock requirements, the presented concept is suitable for these purposes as well. At the local level, the presented sizing methodology can be applied to the population needs, while ensuring satisfactory water quality, i.e. the procedures of raw water conditioning, and obtaining drinking water as a 
result. It is important to note that purified wastewater can also be used for irrigation of grass areas, especially in rural areas without significant influence of industry. The use of rainwater, which is particularly significant in volume if it is collected from bigger surfaces (roofs, eaves and similar residential/commercial buildings in urban areas, larger stadiums) satisfies the economic, environmental and social sustainability targets not only for the system analyzed, but also for its environment. This solution fits into global and European strategies and guidelines related to the reduction of greenhouse gasses, increasing the use of renewable energy sources and energy efficiency increase.

Further research would consist of more accurate determination of available quantities of storm water with regard to return periods and probability of occurrence. This would be especially evident in case of collected quantities of rainwater which could, to a larger extent, satisfy the needs for water and reduce the amount of exploited groundwater or water from some other source (natural or artificial lakes and/or water courses). There is also a plan for further sizing of the irrigation system for the balancing periods longer than one day. It is also foreseen to apply the methods of multi-criteria decision methods with respect to economic, environmental and social criteria.

\section{Acknowledgements}

I would like to express gratitude to Mr. Marin Bosilj, president of municipality "'Sveti Ilija', to Mr. Zlatko Šahmazar, Mr. Marijan Kumrić and Mr. Josip Ćuk from football club 'Obreš", and to my colleague Mr. Mario Svrta, for their support, technical assistance and advices regarding idea of irrigation system

\section{References}

[1] B. Boizidi, "New sizing method of PV water pumping systems," Sustainable Energy Technologies and Assessments, vol. 4, pp. 1-10, 2013.

[2] B. Đurin, and J. Margeta, "Analysis of the possible use of solar photovoltaic energy in urban water supply systems," Water, vol. 6, pp. 1546-1561, 2014.

[3] S. S. Chandel, M. Nagaraju Naik, and R. Chande, "Review of solar photovoltaic water pumping system technology for irrigation and community drinking water supplies," Renewable and Sustainable Energy Reviews, vol. 49, pp. 1084-1099, 2015.

[4] Y. Bakelli, A. A. Hadj, and B. Azoui, "Optimal sizing of photovoltaic pumping system with water tank storage using LPSP concept," Solar Energy, vol. 85, pp. 288-294, 2011.
[5] M. S. Y. Ebaid, H. Qandil, and M. Hammad, "A unified approach for designing a photovoltaic solar system for the underground water pumping well-34 at Disi aquifer," Energy Conversion and Management, vol. 75, pp. 780-795, 2013.

[6] A. A. Ghoneim, "Design optimization of photovoltaic powered water pumping system," Energy Conversion and Management, vol. 47, pp. 1449-1463, 2006.

[7] A. Hamidat, and B. Benyoucef, "Systematic procedures for sizing photovoltaic pumping system, using water tank storage," Energy Policy, vol. 37, pp. 1489-1501, 2009.

[8] B. Đurin, "Sustainability of the urban water supply system operating," $\mathrm{PhD}$ thesis (on Croatian), Faculty of Civil Engineering, Architecture and Geodesy, University of Split, Split, Croatia, 2014.

[9] Google maps, location of Sveti Ilija and football field F.C. Obreš, https://www.google.hr/maps/, (Access Date: 20 July, 2015).

[10] Adria24, http://www.adria24.hr/destinacije/, (Access Date: 27 December, 2015).

[11] B. Hlevnjak, S. Strelec, and J. Jasmin, "Hydrogeological Conditions of Occurrence of Clay Interbed within Varaždin Aquifer," (on Croatian), Inženjerstvo okoliša, vol. 2, pp. 73-81, 2015.

[12]Buy

Irrigation, https://buyirrigation.wordpress.com/tag/football-pitchirrigation/, (Access Date: 28 July, 2015).

[13] SODA-Solar Radiation Data-Solar Energy Services for Professionals, http://www.sodais.com/eng/services/services_radiation_free_eng.php,

(Access Date: 2 August, 2015).

[14] Meteorological and Hydrological Service (MHSC), "Meteorological and hydrological data for Varaždin from 2004. till 2014.," (In Croatian), MHSC: Zagreb, Croatia, 2015.

[15] PVInsights, http://pvinsights.com/RetailerPrice.php, (Access Date: 11 September, 2015.

[16] Pipelife, "Price list," Sveta Nedelja, Croatia, 2014.

[17] E. Hau, "Wind Turbines: Fundamentals, Technologies, Application, Economics," 2nd edition, Springer - Verlag: Berlin, Heidelberg, 2006.

[18] SolarnoHr, http://www.solarno.hr/ (Access Date: 10 September, 2015). 